\title{
SHOULD OMEGA-3 FATTY ACIDS BE USED FOR ADJUVANT TREATMENT OF
}

\section{CANCER CACHEXIA?}

Daryna Sergiyivna Lavriv

Orientadora: Prof. ${ }^{a}$ Doutora Paula Ravasco Laboratório de Nutrição da

Faculdade de Medicina da Universidade de Lisboa 2014/2015 


\section{Abstract}

Objectives: Cancer cachexia is characterised by a progressive loss of muscle, resulting in functional impairment and shorter survival. Therefore, omega-3 has been studied for its role as an anti-cachectic therapy. This systematic review identified studies published on use of omega-3 in cancer cachexia in order to examines the potential benefit. Methods: A systematic literature search of the PubMed database and B-on database was conducted in March 2015 to identify studies published between 2000 and 2015. Of 140 publications, 7 were selected on the basis of their methodological quality, according to the Delphi List. The collected data was summarized and written in text format and in tables. Results: Only one study, made in precachectic population, show statistically and clinically positive intervention. No benefits were observed with the $4 \mathrm{~g}$ EPA/day, but a potentially clinically relevant treatment effect with $2 \mathrm{~g}$ EPA/day. Lung tumors showed the highest CRP levels and while the weight of patients with gastrointestinal cancer increased significantly, patients with lung cancer showed no significant response. Conclusions: Future cachexia trials would likely benefit from studying a single tumor type with earlier stage disease, with probably different dosage depending on the type and inflammation profile.

\section{Resumo}

Objetivos: A caquexia do cancro caracteriza-se por uma progressiva perda de massa muscular, que resulta num prejuízo funcional e numa diminuição da sobrevida. Tendo isso em conta, tem sido estudado o papel do ómega-3 na terapêutica da caquexia. Esta revisão sistemática identificou os estudos publicados acerca do uso do ómega-3 na caquexia do cancro por forma a identificar o potencial beneficio. Métodos: Uma pesquisa sistemática da literatura na base de dados PubMed e B-on foi realizada em Março de 2015, por forma a identificar estudos publicados entre 2000 e 2015. Das 140 publicações, 7 foram selecionadas com base na sua qualidade metodológica, de acordo com a Lista de Delphi. A informação obtida foi resumida e escrita em formato de texto e tabelas. Resultados: Apenas um estudo, realizado numa população pré-caquética, revelou a intervenção como sendo estatisticamente e clinicamente positiva. Não foram observados benefícios com $4 \mathrm{~g}$ de EPA/dia, mas um potencial efeito clinicamente relevante foi observado com $2 \mathrm{~g}$ de EPA/dia. O cancro do pulmão demonstrou os níveis 
de PCR mais elevados e enquanto que o peso dos doentes com cancro gastrointestinal aumentou significativamente, os doentes com cancro do pulmão não demonstraram uma resposta significativa. Conclusões: Futuros ensaios acerca da caquexia poderiam provavelmente beneficiar em estudar um único tipo de tumor, em estádios mais precoces, e com dosagens diferentes conforme o tipo de tumor e o seu perfil inflamatório. 


\section{Methodology}

\section{Literature search}

A systematic literature search of the PubMed database and B-on database was conducted in March 2015 to identify studies published on use of omega-3 in cancer cachexia. The following search terms were used: "omega 3 +treatment of cancer", "omega 3+cachexia" and "omega 3+nutricional state+cancer". There was time restriction, between 2000 and 2015. In the PubMed database one filter was used: "humans". A total of 140 records were identified. Three of these in duplicated form and were removed. From 137 screened, 41 full text articles were assessed eligibility criteria, 103 were excluded and 34 were included. From included, 2 were "systematic review", 10 were "review", 8 were "others" (theoretical records, comments) and 14 were "clinical trial".

Studies were included if: 1) humans; 2) evaluate the following outcomes: weight and/or body composition and/or nutritional state and/or quality of life; 3) use of omega3 in cancer patients. Studies were excluded if: 1) evaluate solely the effect in tumor progression and/or in emergence of metastasis and/or in enhancing chemo or radiotherapy effect; 2) association of omega-3 with another substance which is not also present in controlled group.

\section{Study quality}

The methodological quality of the 14 selected studies was evaluated using the Delphi List (Jadad et al 1996). Below 3 points the study is considered as having low quality, therefore 7 studies were excluded (Figure 1). 


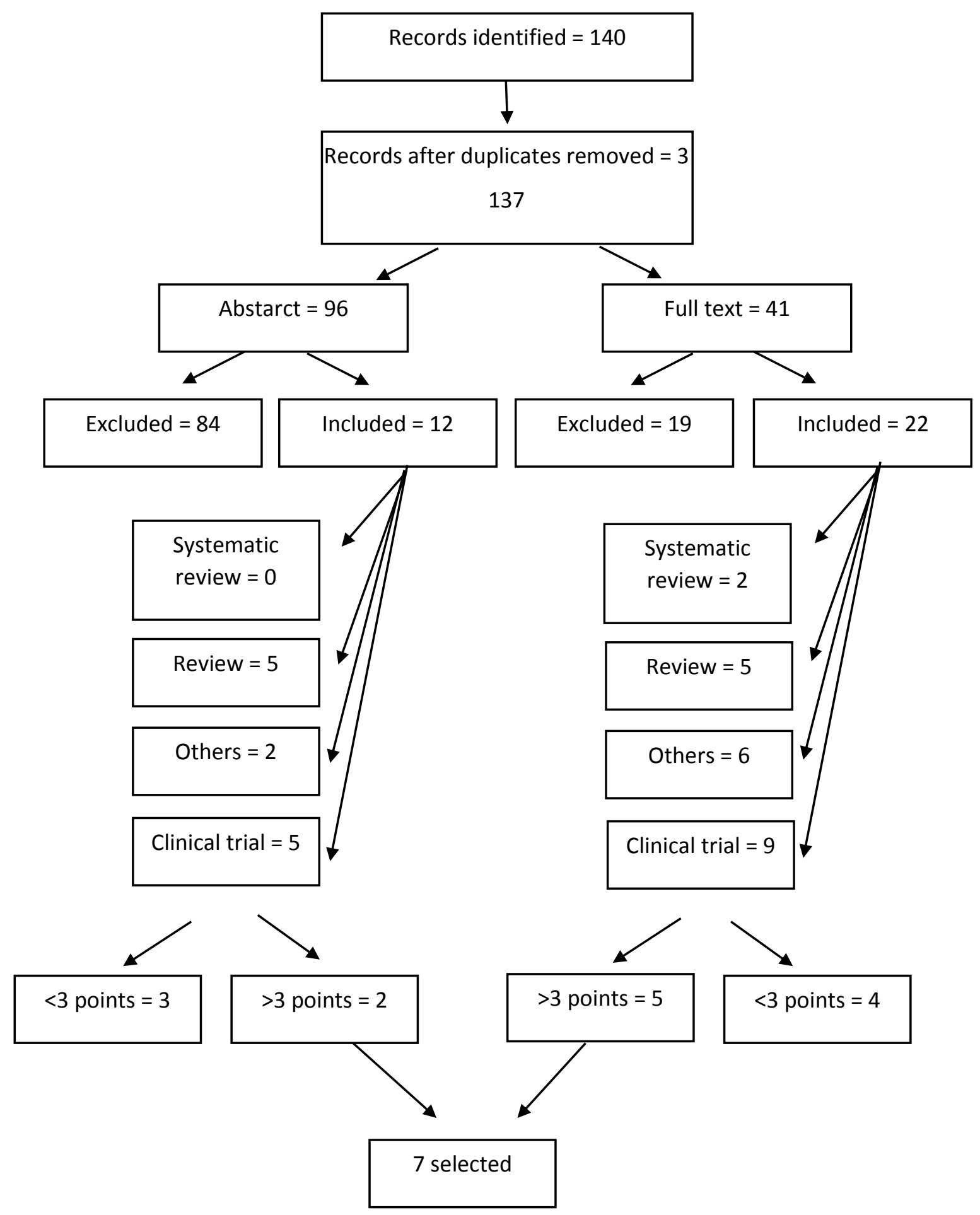

Figure 1. Study design, literature search and article selection 


\section{Introduction}

\section{Fatty acids}

Fatty acids, once solely thought as an energy source, have been shown to be highly active substances. They can act as transcription factors that regulate protein synthesis as ligands in signal transduction, and as membrane components that regulate the fluidity, permeability, and dynamics of cell membranes (2). There are 3 types of naturally occurring fats: saturated, monounsaturated and polyunsaturated (1). The bonds between carbons in saturated fatty acids are fully saturated with hydrogen and are single bonds. Monounsaturated fatty acids and polyunsaturated fatty acids (PUFAs) have bonds that are not saturated with hydrogen, thus one or more double bonds connect the molecule carbons (6).

\section{Omega-3 fatty acids}

Polyunsaturated fats can be classified into 2 groups based on the position of the first double bond site: omega-3 fatty acids or omega-6 fatty acids (1). Mammals, including humans, can synthesize saturated fatty acids and monounsaturated (n-9) ones, but cannot synthesize either the (n-6) or the (n-3) double bond fatty acids (6). The most prominent omega- 6 fatty acids in the human diet are arachidonic acid (AA) (found in animal meat) and linoleic acid (LA) (found in vegetable oils, seeds, nuts), which can be converted in arachidonic acid by desaturase enzyme (1).

Major dietary sources of omega-3 are fatty fish such as mackerel, herring, salmon, sardines, pilchards and kippers containing eicosapentaenoic acid (EPA) and docosahexaenoic acid (DHA) (5), as well as nuts, seeds, and vegetable oils containing $\alpha$-linolenic acid (ALA) that can be converted into EPA and then DHA by the same desaturase enzyme (1). Isotope-labelled ALA feeding trials have shown the conversion of ALA to EPA to vary from $0.2 \%$ to $21 \%$ and that of ALA into DHA to vary between $0 \%$ and to $9 \%(1)$.

ALA does not usually accumulate to particularly high concentrations even when ingested at relatively high dietary levels. This is partly due to the fact that much of the dietary ALA undergoes $\beta$-oxidation in the mitochondria and very limited amount is available for its conversion to EPA and DHA. (3) It is also known that increased amount of LA slows down the metabolism of ALA to EPA and DHA by inhibiting desaturase (3). 
The ratio of omega-6/omega-3 intake is estimated to be 20 to 1 in the modern Western diet, compared with that of our palaeolithic ancestors who ate a diet much richer in omega-3's: estimated omega-3/omega-6 ratio of 2:1 (1). Nowadays, meat and fish contain less omega-3 and more omega- 6 fatty acids than in the past, secondary to the use of commercial rations with high content of omega- 6 and low in omega- 3 . Even cultivated vegetables are poorer in omega-3 when compared with wild plants (1). About 95-99\% of the population eats lesser than the required $\omega-3$ fatty acids for a good health (3). The metabolism of omega-3's and omega-6's leads to the creation of the metabolites named eicosanoids that are a class of bioactive molecules, which include prostaglandins, thromboxanes (due to COX activity) and leukotrienes (due to LOX) (1, 5). Eicosanoids derived from omega-6's are 2-series prostanoids (thromboxane A2, prostaglandin E2 and prostacyclin2) and 4-series leukotrienes (leukotriene B4 and leukotriene $\mathrm{C} 4$ ) and are generally pro-inflammatory and pro-aggregation, whereas those derived from omega-3's are 3-series prostanoids and 5-series leukotrienes and are predominantly anti-inflammatory and inhibit platelet aggregation $(1,5,6)$.

Adverse effects of EPA and other n-3 fatty acids were reported in few studies. Most usual gastrointestinal effects are mild abdominal discomfort, flatulence or nausea, transient diarrhoea or steatorrhoea. Some studies reported fish aftertaste (4). Presently, a number of alternative sources of omega-3 fatty acids have been or are being developed. For example, oils naturally enriched in DHA are being extracted from cultured microorganisms like the algae Crypthecodinium cohnii and are now being used to fortify a number of products, including baby formula. Similarly, novel plants like Echium plantagineum are being cultivated because their seed oil naturally contains stearidonic acid, an intermediate in the metabolism of omega-3 fatty acids, that appears to be metabolized much more efficiently than $\alpha$-linolenic acid, resulting in an enrichment of tissues with EPA and DHA following its consumption. Finally, a number of companies have developed transgenic varieties that can produce seed oils that are highly enriched with stearidonic, EPA and DHA acids (7).

\section{Cancer cachexia}

Cancer-induced cachexia (CIC) is experienced by up to $80 \%$ of patients with advanced cancer, particularly those with gastrointestinal, pancreatic, and head-neck malignancies. CIC has been implicated in up to $20 \%$ of cancer-related deaths (9). The 
European Palliative Care Research Collaborative (EPCRC) has defined CIC as follows: "Cancer cachexia is a multi-factorial syndrome defined by an ongoing loss of skeletal muscle mass (with or without loss of fat mass) that cannot be fully reversed by conventional nutritional support and leads to progressive functional impairment" (4). Besides that, cachexia can be also characterised by anorexia, early satiety, changes in taste perception, weight loss, weakness, anaemia and oedema, all affecting appetite and diet (5). Fearon et al have proposed a clinical definition of CIC supported by the latest research that included three factors: weight loss $>10 \%$, low caloric intake $<1500$ $\mathrm{kcal} /$ day, and systemic inflammation as measured by a CRP $>10 \mathrm{mg} / \mathrm{L}$ (9).

It is also known that weight loss negatively affects patient's ability to tolerate chemotherapy and radiotherapy, and weight loss approaches $30 \%$ of baseline pretreatment weight (9). There is an association between cachexia and shorter survival as well as poor Quality of Life (QoL) (5). Multiple biologic pathways are involved in this process, including immune response, neuroendocrine hormones and tumour specific factors such as proteolysis inducing factor (PIF) (10). The immune response consists in increased immunological factors such as the cytokines interleukin-1 (IL-1), interleukin6 (IL-6), Interferon $\gamma$ (IFN- $\gamma$ ) and Tumour Necrosis Factor-Alpha (TNF- $\alpha$ ) (5). These cytokines have been found to lead to hypermetabolism and increased hepatic amino acid uptake and protein synthesis: acute-phase proteins, such as CRP, fibrinogen, and serum amyloid peptide $(5,9)$. They are also responsible for accelerated muscle and adipose tissue breakdown, induction of gluconeogenesis, activation of NF- $\mathrm{KB}$ and stimulation of the production of arachidonic metabolites. On the other hand, leukotriene B4 and thromboxane A2 are considered stimulators of TNF- $\alpha$ and IL-1 production $(5,9)$.

Of note that many studies have attributed the cause of muscle proteolysis to the ubiquitin-proteasome pathway and to a dysregulation of the dystrophin glycoprotein complex (DGC). Initiated by NF- $\kappa \mathrm{B}$, ubiquitin molecules attach to a muscle protein marking it for degradation in the large tube-like proteasome. The DGC is a collection of proteins that anchors muscle sarcomeres and protects them during muscle contraction (9). For these reasons, cytokines are regarded as the driving force behind cancer cachexia and are considered to be both tumour and host derived (5).

Neuroendocrine hormones, e.g. leptin, ghrelin, and serotonin, when reaching the brain hypothalamic region, play a central role in balancing the orexigenic and anorexigenic signals. Their cytokine-driven dysregulation lead to decreased food intake and increased resting energy expenditure (REE) (11). 
On the other hand, a tumour product, PIF, initiates muscle protein degradation directly through activation of the proteasome pathway (12). One single therapy may not be completely successful in the treatment of cachexia. Treatments involving different combinations are more likely to be successful (11).

\section{Omega-3 and cachexia}

Omega-6 arachidonic acid (AA) and the cyclooxygenase-2 (COX-2) enzyme are both found in abundance in most cancer tissues, but the concentrations of omega-3 fatty acids DHA and EPA are usually lower compared to normal tissues (2). Beneficial effects may be mediated through several different mechanisms, including alteration in cell membrane composition, gene expression or eicosanoid production (3). Dietary omega-3 fatty acids directly affect AA metabolism because they displace AA from membranes and compete with AA for the enzymes that catalyse the biosynthesis of eicosanoids. The enrichment of monocyte membranes with omega-3 fatty acids results in the synthesis and secretion of reduced quantities of cytokines (e.g. TNF- $\alpha$, IL-1 $\beta$ ) (5, 7, 13). Recent studies have shown that n-3 fatty acids may attenuate protein degradation, potentially by preventing NF-kB accumulation in the nucleus, preventing the degradation of muscle proteins (12). Furthermore, the effects of PIF are also inhibited by EPA (10). This suggest that n-3 PUFAs may have an important role in nutritional support of cancer patients if they can be administered in such a way that high doses can be achieved for prolonged periods of time with limited gastrointestinal side effects (13), Table 1.

Reported positive outcomes related to cachexia include diminished weight loss, increased appetite, improved Quality of Life and prolonged survival in weight-losing cancer patients (5), Table 1. Besides acting in cachexia, several experimental studies have reported an association between dietary fish oil and attenuation of side effects of anti-neoplastic therapies and enhanced cytotoxicity of drugs in tumour cells (9). However, some trials failed to show a significant benefit in cachexia, Table 2. There are several reasons for discordance, including the time at which intervention was initiated (early or later stages), contamination between treatment arms (9), selection of primary outcome markers such as weight, which has been shown to be confounded by hydration (12) and indirect assessments of muscle mass (9). Most studies used bioelectrical impedance analysis for assessment of the body composition. Measurement works well 
in healthy subjects with stable water and electrolyte balance. However, it is not validated for patients with extreme BMI ranges or with abnormal hydration, where it can both over- or underestimate muscle mass significantly (4).

Moreover, patients with advanced cancer are often unable to complete the study intervention time and are unable to consume the therapeutic dose of omega- 3 fatty acids due to anorexia, dysgeusia or dysphagia from chemotherapy and radiation (9). Megestrol Acetate (MA) is a synthetic derivate of progesterone (9) and is currently considered the best available treatment option for cancer-related cachexia, and it is the only drug approved in Europe (11). Studies show that various doses of MA stimulate appetite and increase weight gain (9) by inducing the release of neuropeptide $\mathrm{Y}$ in the CNS (11). However, less than $30 \%$ of patients experience short-term appetite stimulation (11) and more detailed body composition studies suggest that the weight gain is largely an increase in fat mass, while performance status and QoL are generally not affected. There was also no difference between MA and placebo on survival. (9). 
Table 1. Statistically and clinically positive intervention studies with EPA and/or DHA and outcomes

\begin{tabular}{|c|c|c|c|c|}
\hline $\begin{array}{l}\text { Author } \\
\text { (year) }\end{array}$ & $\begin{array}{l}\text { Population and study } \\
\text { design }\end{array}$ & Intervention & Outcomes & Results \\
\hline $\begin{array}{r}\text { Van } \\
\text { der } \\
\text { Meij, } \\
\text { et al } \\
2010 \\
(14)\end{array}$ & $\begin{array}{l}40 \text { patients } \\
\text { Lung cancer (stage IIIa-N2 } \\
\text { or IIIb NSCLC) } \\
\text { Double-blind, randomized, } \\
\text { controlled trial }\end{array}$ & $\begin{array}{l}\text { Intervention group: } 2 \text { cans/day of fish- } \\
\text { oil enriched oral nutritional } \\
\text { supplement, energy+protein-dense } \\
\text { (2.02g/day EPA+0.92g/day DHA); } \\
\text { Control group: isocaloric oral } \\
\text { nutritional supplement without } \\
\text { EPA+DHA; } \\
\text { Follow-up during } 5 \text { weeks from the } \\
\text { start of concurrent chemoradiotherapy; }\end{array}$ & $\begin{array}{l}\text { Weight } \\
\text { BIA: FFM (Hydra } \\
\text { 4200) } \\
\text { MUAMC } \\
\text { REE }\end{array}$ & $\begin{array}{l}\text { EPA group: weight maintenance (weight } \\
\text { difference between intervention group and } \\
\text { control group: } 1.3 \mathrm{~kg}, \mathrm{p}=0.02 \text { at } 2 \text { weeks and } 1.7 \\
\mathrm{~kg}, \mathrm{p}=0.04 \text { at } 4 \text { weeks); } \\
\text { Less decrease in FFM (FFM difference between } \\
\text { intervention group and control group }(1.5 \mathrm{~kg} \text { at } 3 \\
\text { weeks ( } \mathrm{p}=0.05 \text { ) and } 1.9 \mathrm{~kg} \text { at } 5 \text { weeks }(\mathrm{p}=0.02) \text { ); } \\
\text { Increased MUAMC, while the MUAMC in the } \\
\text { control group decrease (difference between } \\
\text { groups not significant at } 5 \text { weeks } \mathrm{p}=0.06) \text {. } \\
\text { Compared with the } \mathrm{C} \text { group, the REE in the I } \\
\text { group decreased more after } 3 \text { weeks }(\mathrm{B}=-16.7 \% \\
\text { of predicted, } \mathrm{P}=0.01 \text { ). }\end{array}$ \\
\hline $\begin{array}{r}\text { Van } \\
\text { der } \\
\text { Meij, } \\
\text { et al } \\
2012 \\
(15)\end{array}$ & $\begin{array}{l}40 \text { patients } \\
\text { Lung cancer (stage IIIa-N2 } \\
\text { or IIIb NSCLC) } \\
\text { Double-blind, randomized, } \\
\text { controlled trial }\end{array}$ & $\begin{array}{l}\text { Intervention group: } 2 \text { cans/day of fish- } \\
\text { oil enriched oral nutritional } \\
\text { supplement, energy+protein-dense } \\
\text { (2.02g/day EPA+0.92g/day DHA); } \\
\text { Control group: isocaloric oral } \\
\text { nutritional supplement without } \\
\text { EPA+DHA; } \\
\text { Follow-up during } 5 \text { weeks from the } \\
\text { start of concurrent chemoradiotherapy; }\end{array}$ & $\begin{array}{l}\text { Quality of life } \\
\text { (EORTC-QLQC30 } \\
\text { questionnaire; } \\
\text { Karnofsky } \\
\text { Performance } \\
\text { Status); } \\
\text { Physical activity } \\
\text { (PAM } \\
\text { accelerometer, } \\
\text { model AM101); } \\
\text { Handgrip strength } \\
\text { (hydraulic hand } \\
\text { dynamometer, } \\
\text { Baseline); }\end{array}$ & $\begin{array}{l}\text { After } 3 \text { weeks, the I group had a higher } \\
\text { Karnofsky Performance Status than the C group } \\
(\mathrm{p}=0.04) \text { and after } 5 \text { weeks, showed a } \\
\text { significantly better global health status, physical } \\
\text { function, cognitive function and social function } \\
\text { on the EORTC ( } \mathrm{p}=0.04, \mathrm{p}<0.01, \mathrm{p}<0.01, \mathrm{p}= \\
0.04) \text {; } \\
\text { During week } 3 \text { and } 5 \text {, the I group tended to have } \\
\text { a higher daily physical activity score ( } \mathrm{p}=0.04, \mathrm{p}= \\
0.05) \text {; } \\
\text { Handgrip strength did not significantly differ } \\
\text { between the groups; }\end{array}$ \\
\hline
\end{tabular}


Table 2. Statistically and clinically negative intervention studies with EPA and/or DHA or echium oil and outcomes

\begin{tabular}{|c|c|c|c|c|}
\hline Author(year) & $\begin{array}{l}\text { Population and study } \\
\text { design }\end{array}$ & Intervention & Outcomes & Results \\
\hline $\begin{array}{r}\text { Moses, et al } \\
2004 \\
(16)\end{array}$ & $\begin{array}{l}24 \text { patients } \\
\text { (9 in intervention vs. } 15 \\
\text { in control group) } \\
\text { Pancreatic cancer } \\
\text { Double-blind, } \\
\text { randomized, controlled } \\
\text { trial }\end{array}$ & $\begin{array}{l}\text { Intervention group: fish-oil enriched } \\
\text { oral nutritional supplement } 2 \text { cans/day } \\
(2,2 \mathrm{~g} \text { EPA }+0.96 \mathrm{~g} \text { DHA/day) } \\
\text { Control group: identical oral nutritional } \\
\text { supplement without } \mathrm{n}-3 \text { fatty acids. } \\
\text { Follow-up at } 8 \text { weeks from baseline }\end{array}$ & $\begin{array}{l}\text { Weight } \\
\text { BIA: LBM } \\
\text { (Xitron Hydra, Xitron } \\
\text { Technologies@) } \\
\text { REE (indirect } \\
\text { calorimetry, } \\
\text { Deltatrac); } \\
\text { TEE, PAL and EEA } \\
\text { (DLW, doubly } \\
\text { labelled water) }\end{array}$ & $\begin{array}{l}\text { No significant changes in weight or LBM in } \\
\text { either group over } 8 \text { weeks of } \\
\text { supplementation vs. baseline values. } \\
\text { No statistically significant differences } \\
\text { between groups in REE, TEE, PAL and } \\
\text { EEA. However, when compared with } \\
\text { baseline values, TEE, EEA and PAL } \\
\text { increased significantly in intervention } \\
\text { group; }\end{array}$ \\
\hline $\begin{array}{r}\text { Jatoi, et al } \\
2004 \\
(17)\end{array}$ & $\begin{array}{l}421 \text { patients; different } \\
\text { cancers excluding } \\
\text { brain, prostate, } \\
\text { gynecologic. } \\
\text { Multicenter, double- } \\
\text { blind, randomized trial }\end{array}$ & $\begin{array}{l}3 \text { groups: EPA supplement (refined, } \\
\text { deodorized sardine oil, with } 1.09 \mathrm{~g} \text { of } \\
\text { EPA and } 0.46 \mathrm{~g} \text { of docosahexaenoic } \\
\text { acid), } 2 \text { cans/day + placebo; MA, } \\
600 \mathrm{mg} / \text { day }+ \text { isocaloric, isonitrogenous } \\
\text { placebo; EPA supplement, } 2 \text { cans/day + } \\
\text { MA } 600 \mathrm{mg} / \text { day. } \\
\text { Follow-up weekly for } 4 \text { weeks and then } \\
\text { monthly. }\end{array}$ & $\begin{array}{l}\text { Weight } \\
\text { Appetite (NCCTG } \\
\text { questionnaire and } \\
\text { FAACT } \\
\text { questionnaire) } \\
\text { Survival } \\
\text { Global quality of life } \\
\text { (Uniscale) }\end{array}$ & $\begin{array}{l}\text { No significant change in weight with EPA } \\
\text { alone or in combination with MA. } 6 \% \\
\text { patients taking EPA supplement gained } \\
\geq 10 \% \text { baseline weight } v s 18 \% \text { of patients } \\
\text { taking MA (p=0.01). MA alone was more } \\
\text { effective for weight gain: } 1.3 \mathrm{~kg} v s-1.0 \mathrm{~kg} \\
\text { in the EPA-treated arm, } \mathrm{p}=0.008 \\
\text { However, when weight gain was evaluated } \\
\text { with increments of less than } 10 \% \text { weight } \\
\text { increase, there seemed to be no significant } \\
\text { differences among the arms; } \\
\text { Appetite, as measured by the NCCTG, } \\
\text { showed comparable effect among groups. } \\
\text { The FAACT suggest that MA provided } \\
\text { better appetite stimulation than EPA alone } \\
\text { (p=0.004); } \\
\text { There were no statistically significant }\end{array}$ \\
\hline
\end{tabular}


Fearon, et al 518 patients

2006 Advanced

(18) gastrointestinal $(\mathrm{n}=287)$ and lung $(n=231)$

cancer

Multicenter, double-

blind, randomized,

controlled trial (1)

C.A.Pastore, 69 patients;

et al Gastrointestinal tract

2014 (including liver,

(19) gallbladder and pancreas) or lung cancer, chemotherapynaïve;

Randomized, single-
Intervention group: $1 \mathrm{~g}$ soft gelatin capsules of $95 \%$ EPA diester; Two

EPA doses tested: $2 \mathrm{~g}$ EPA/day and $4 \mathrm{~g}$ EPA/day;

Control group: medium chain

triglycerides;

Follow-up at 8 weeks from baseline;

Weight (spring balance scales, Scale model 1618);

BIA: LBM

(Bodystat $1500 \AA$

bioelectrical

impedance analyser);

Physical function

(EORTC);

Weakness (self-

reported);

Survival;

Karnofsky

performance

status(KPS);

CRP;

Intervention group: three $125 \mathrm{~mL}$ units of ONS enriched with EPA (600kcal,

$33 \mathrm{~g}$ protein and 2,2g EPA) per day;

Control group: two $200 \mathrm{~mL}$ units of

standart ONS (600kcal, 24g protein)

per day;

Start 3 days before first chemotherapy

and follow-up at 4 weeks from differences in median survival and in quality of life ( $\mathrm{p}=0.82$ and $\mathrm{p}=0.93$

respectively);

No statistical difference for weight and

LBM between groups ( $p=0.066$ and $p=0.14$, respectively);

By comparison with control group, the group receiving $2 \mathrm{~g}$ EPA/day had a mean increase of $1.2 \mathrm{~kg}$ of weight and of $0.9 \mathrm{~kg}$ of LBM and group receiving $4 \mathrm{~g}$ EPA had a mean increase of $0.3 \mathrm{~kg}$ of weight and a mean decrease of $0.1 \mathrm{~kg}$ of LBM;

There was a statistically significant difference in physical function, which improved by $7 \%$ in those receiving $2 \mathrm{~g}$ EPA $(\mathrm{p}=0.04)$ and fell $5 \%$ in those receiving $4 \mathrm{~g}$ EPA;

Weakness tended to decrease in the $2 \mathrm{~g}$ EPA;

Median survival: 140 days (placebo), 155 (2g EPA), 142 (4g EPA);

There were no differences for KPS or CRP;

us-CRP In the intention-to-treat analysis (57 pats)

(Immunoturbidimetry, and in protocol analyses (43 pats) there was CRP Turbiquest $\left.{ }^{\circledR}\right)$; not significant difference between

intervention group and control group in CRP values $(-0.5 \mathrm{mg} / \mathrm{dL}$ vs. -0.7 $\mathrm{mg} / \mathrm{dL}(\mathrm{p}=0,6)$ and $-2.35 \mathrm{mg} / \mathrm{dL}$ vs. -0.7 $\mathrm{mg} / \mathrm{dL}(\mathrm{p}=0,8)$ respectively);

There is however a nonsignificant trend 
blind, controlled trial;

Pottel, et al 83 patients;

2014 Squamous cell

(20) carcinoma of the head and neck ( except tumours of the parotid gland, nasal cavity, paranasal sinuses and glottic cancer); Multicenter, doubleblind, randomized, controlled trial; baseline;

Intervention group: $7.5 \mathrm{ml}$ b.i.d of Weight echium oil (BioMega SDA®, containing $235 \mathrm{mg} / \mathrm{ml}$ ALA $+95 \mathrm{mg} / \mathrm{ml}$ $\mathrm{SDA}+79 \mathrm{mg} / \mathrm{ml}$ GLA)

Control group: $7.5 \mathrm{ml}$ b.i.d of sunflower oil (Sunflower Oil High Oleic) without n-3 fatty acids.

Follow-up weekly for 7 weeks toward a decrease in the EPA group;
BIA: LBM

(BIA 101; DXA;

Hand grip strength

(JAMAR®)
No significant difference in weight loss was observed between the I group and $\mathrm{C}$ group (8.9\% and $7.6 \%, \mathrm{p}=0.303$ );

After 4 weeks, a significant decrease in FFM ( $\mathrm{I}=-5.10 \%, \mathrm{C}=-4.12 \%, \mathrm{p}<0.01)$, LBM (I $=-3.77 \%, C=-2.41 \%, \mathrm{p}<0.01)$ and FM ((I:-4.04\%, C:-3.66\%, P<0.05) was observed with DXA;

Relative median decrease in grip strength was comparable between groups ( $\mathrm{I}=$ $0.86 \%, \mathrm{C}=-0.78 \%, \mathrm{p}>0.05$ )

$\boldsymbol{A L A}$ : $\alpha$-linolenic acid; BIA: Bioelectric Impedance Analysis; $\boldsymbol{D H A}$ : docosahexaenoic acid; $\boldsymbol{D L H}$ : doubly labelled water; $\boldsymbol{D} \boldsymbol{X A}$ : dual energy X-ray absorptiometry; EEA: energy expenditure of activity; EORTC: European Organisation for Research and Treatment of Cancer (Quality of Life Questionnaire-C30 version 3.0); EPA: eicosapentaenoic acid; FAACT: Functional Assessment of Anorexia/Cachexia; FM: fat mass; FFM: free fat mass; $\boldsymbol{G L A}$ : $\gamma$-linolenic acid; $\boldsymbol{L B M}$ : lean body mass; $\boldsymbol{M A}$ : megestrol acetate; $\boldsymbol{M M}$ : muscle mass; $\boldsymbol{M U A M C}$ : mid-upper arm muscle circumference; MUAC: mid-upper arm circumference; NCCTG: North Central Cancer Treatment Group; $N S$ : not significant; $N S C L C$ : non-small cell lung cancer; $\boldsymbol{O N S}$ : oral nutricional supplement; PAL: physical activity level; PAM: physical activity monitor; $\boldsymbol{R E E}$ : resting energy expenditure; $\boldsymbol{S D A}$ : stearidonic acid; $\boldsymbol{T S F}$ : tríceps skinfold thickness; $\boldsymbol{T E E}$ : total energy expenditure; $\boldsymbol{u} \boldsymbol{s}-\boldsymbol{C R P}$ : ultrasensitive CRP; 


\section{Results}

Seven studies provided data from 1155 patients, met the selection criteria and were included. In five studies, the intervention group received cans of supplement enriched with EPA or EPA + DHA vs the control group that received similar supplements as the intervention group, but without EPA or DHA. One study (17) evaluated the differences of outcomes between MA alone, EPA alone and MA + EPA. In another study (20) the intervention group received echium oil and the control group receive sunflower oil. The outcomes evaluated were weight, body composition (BIA), MUAMC, Quality of Life (EORTC-QLQC30 and Karnofsky), physical activity, handgrip strength, REE, appetite, survival and CRP. The follow-up ranged between 4 and 8 weeks, and the study by Jatoi, et al 2004, lasted up to 3 months.

\section{Statistically positive intervention}

Only one study $(14,15)$ showed both statistically and clinically positive intervention; 42 patients with stage III NSCLC were enrolled and allocated to the intervention or control group, and 40 eligible patients were included. This stage corresponded to patients with localised or loco-regional disease, which received multimodal treatment (concurrent chemo-radiotherapy), followed by surgery with curative intent. Stage IV NSCLC patients were not included, had the shortest survival and were treated by palliative chemotherapy. These patients received 2 cans/day of either a protein- and energy-dense oral nutritional supplement containing n-3 PUFA, providing $2.02 \mathrm{~g} / \mathrm{d}$ EPA+0.92 g/d DHA (480 mL ProSure ${ }^{\circledR}$ ) or an isocaloric control oral nutritional supplement without EPA and DHA (400mL Ensure®) during 5 weeks from the start of concurrent chemo-radiotherapy. The results showed that patients consumed supplements only $\sim 1$ can/day during chemo-radiotherapy.

The outcomes described in the 2010 trial (14) were weight, Fat Free Mass (FFM), Mid-Upper Arm Circumference (MUAC) and Resting Energy Expenditure (REE). After 1, 2 and 4 weeks, the intervention group (IG) had a better weight maintenance than the control group $(\mathrm{CG}),(\mathrm{B}$ (absolute differences between the IG and $\mathrm{CG})=1.1 \mathrm{~kg}, p=0.07 ; \mathrm{B}=1.3 \mathrm{~kg}, p=0.02 ;$ and $\mathrm{B}=1.3 \mathrm{~kg}, p=0.02$;) this effect was stronger in the per protocol analysis $(\mathrm{B}=2.2 \mathrm{~kg}, p<0.01 ; \mathrm{B}=2.2 \mathrm{~kg}, p<0.01$; and $\mathrm{B}=2.2 \mathrm{~kg}, p=0.04$, respectively). Besides that, when selecting patients with increased plasma phospholipid EPA concentrations, a more adequate preservation of body weight was shown, 
confirming that these effects could be ascribed to n-3 fatty acids supplementation. Over time, FFM in both groups decreased, but less in the IG than in the CG after 3 and 5 weeks $(\mathrm{B}=1.5 \mathrm{~kg}, p=0.05$ and $\mathrm{B}=1.9 \mathrm{~kg}, p=0.02$, respectively). The MUAC of the IG increased during chemo-radiotherapy, tending to be $1 \mathrm{~cm}$ wider after 5 weeks, whereas MUAC in the CG decreased ( $p=0.06$ ). At baseline, REE of the study population was $112 \%$ of predicted and not significantly different between groups. Compared with the $\mathrm{CG}$, the REE in the IG decreased more after 3 weeks $(\mathrm{REE}=-16.7 \%$ of predicted, $p=0.01)$.

The outcomes described in 2012 trial (15) were QoL and functional status (performance status, handgrip strength and physical activity). In general, patients in the IG had better on QoL scores than patients in the CG. After 3 weeks, the IG had a higher Karnofsky Performance Status (KPS) $(B=5.3, p=0.04)$ than the CG. After 5 weeks, KPS did not differ between groups, but the IG showed a significantly better global health status $(\mathrm{B}=12.2, p=0.04)$, physical function $(\mathrm{B}=11.6, p<0.01)$, cognitive function $(\mathrm{B}=20.7, p<0.01)$ and social function $(\mathrm{B}=22.1, p=0.04)$ on the EORTC-QLQC30 subscales vs the CG. During week 3 and 5, the IG tended to also have a considerably higher daily physical activity score $(\mathrm{B}=6.6, p=0.04$ and $\mathrm{B}=2.5, p=0.05$, respectively), but handgrip strength did not significantly differ between groups.

The required number of patients (as indicated by power calculations) was not achieved in the IG. This might have resulted in a reduced statistical power. However, consistent beneficial effects of n-3 fatty acids were observed on different nutritional variables in this small, pre-cachectic study population. The compliance was also lower than expected, due to anorexia, palatability and early satiety, and patients' preference to consume normal oral food rather than oral nutritional supplements. This confirms the need to develop more feasible methods of n-3 fatty acids supplementation for cancer patients. Compared with previous studies, the present study population showed a less advanced stage of disease and a low prevalence of malnutrition at baseline. Yet, more patients showed signs of pre-cachexia, such as increased levels of serum IL-6 and CRP, anorexia, and reduced muscle strength.

\section{Statistically negative intervention}

Moses, et al 2004 compared the effects of an EPA containing nutritional supplement with those of an isocaloric, isonitrogenous control supplement on weight, 
Lean Body Mass (LBM) and QoL in patients with pancreatic cancer cachexia. A total of 24 patients were included in the study if they had lost more than 5\% of their pre-illness stable weight over the previous 6 months. They were asked to consume two cans/day for an 8 -week period. Supplements were cans of $237 \mathrm{~mL}$ with or without $1.1 \mathrm{~g}$ of EPA. The mean intake of the control supplement was 1.5 cans/day and that of the EPA enriched supplement was 1.9 cans/day. At baseline, patients had a significantly elevated REE when compared with predicted values. Conversely, their Energy Expenditure of Activity (EEA) and Total Energy Expenditure (TEE) were significantly lower than predicted. Compared with baseline values, there were no significant changes in weight or LBM in either group over the 8-week period. However, TEE, EEA and Physical Activity Level (PAL) all increased significantly in those randomised to the $n-3$ enriched supplement, but not in the CG. There were however, no statistically significant differences between groups. Compared with baseline, energy and protein intake also increased significantly in those randomised to the n-3 enriched supplement. The net increase in both protein and energy intake in patients taking the n-3 enriched supplement seemed to translate into an almost parallel increase in TEE with a consequent rise in PAL.

Megestrol Acetate (MA) is a synthetic derivate of progesterone (9) with proven efficacy in increasing appetite and non-fluid weight. It is currently considered the most effective available treatment option for cancer-related cachexia, being the only drug approved in Europe (11). In the study by Jatoi, et al 2004 the aim was to determine whether EPA either alone or in combination with MA improved weight, appetite, QoL, and survival in advanced cancer patients with cachexia, compared with MA alone; 421 patients were deemed eligible and the median number of days on study was slightly more than 3 months. The study compared 3 treatment arms: an EPA supplement (2 cans/day) plus a placebo liquid suspension that seemed identical to MA vs MA liquid oral suspension of $600 \mathrm{mg} / \mathrm{day}$ plus isocaloric, isonitrogenous supplement that seemed identical to the EPA one $v s$ two cans/day of EPA supplement plus MA liquid oral suspension $600 \mathrm{mg} /$ day. Each EPA supplement provided $1.09 \mathrm{~g}$ of EPA and $0.46 \mathrm{~g}$ of DHA. Patients were required to have a self-reported, 2-month weight loss of at least $2.3 \mathrm{~kg}$ and/or a physician-estimated caloric intake of less than 20 calories $/ \mathrm{kg}$ of body weight/day. The primary end point was a $10 \%$ weight gain above baseline. The percentage of patients who experienced such physician-reported weight gain was as follows: $6 \%, 18 \%$, and 11\% EPA-treated, MA-treated, and combination-treated arms, 
respectively $(p=0.01)$. Thus, the primary end point of this trial indicated greater efficacy of the single-agent MA. However, when weight gain was evaluated with increments of less than $10 \%$ weight increase, there seemed to be no significant differences among the arms. Appetite, as measured by the North Central Cancer Treatment Group (NCCTG) questionnaire, showed roughly comparable effects among groups. In contrast, the Functional Assessment of Anorexia/Cachexia (FAACT), suggested that appetite improved over time in the arms that included MA. The fact that the NCCTG questionnaire did not find statistically significant differences in the appetite stimulation degree among treatment arms, suggests that the EPA supplement might actually carry at least modest orexigenic effects. There were no statistically significant differences in median survival in EPA-treated, MA-treated, and combination-treated arms $(p=0.82)$. With regard to global QoL, the Uniscale also detected no significant differences $(p=0.93)$. This trial did not include a pure placebo arm. Hence, MA might have masked some of the favourable effects of EPA.

Fearon, et al 2006 aimed to examine the effects of two distinct doses of EPA: $2 \mathrm{~g} /$ day and $4 \mathrm{~g} /$ day of a $95 \%$ pure EPA diethyl ester against placebo, taken as capsules over a period of at least 8 weeks. Patients surviving beyond 8 weeks were offered EPA diethyl ester on a compassionate use, open label basis. Recruited patients had gastrointestinal and lung cancer with $5 \%$ or more loss of pre-illness stable weight. At baseline, patients had lost approximately $18 \%$ of their pre-illness weight and had a BMI of about $21 \mathrm{~kg} / \mathrm{m}^{2}$ (indicating moderately severe undernutrition). Overall, 518 patients were recruited; the number of patients remaining in the study decreased by approximately $50 \%$ over 8 weeks. The primary endpoint was defined as change in body weight (this study was designed to detect a $2 \mathrm{~kg}$ difference in body weight in the EPAsupplemented group compared with the controls), between baseline and week 8 . Secondary endpoints were survival, changes in LBM, QoL, performance status and CRP between baseline and week 8. Analysis of covariance for weight between the 2 groups at 8 weeks was borderline non-significant $(p=0.066)$. When compared with the placebo group, the mean weight change for the group receiving $2 \mathrm{~g} /$ day of EPA was an increase of $1.2 \mathrm{~kg}$. The Confidence Intervals were consistent with a clinically relevant treatment effect for EPA at this dose. For the group receiving 4g/day of EPA, the mean weight change was an increase of $0.3 \mathrm{~kg}$. Compared with weight at baseline, patients receiving placebo lost a mean of $0.7 \mathrm{~kg}$ over 8 weeks. Those receiving $2 \mathrm{~g}$ EPA daily gained a median of $0.4 \mathrm{~kg}$ and those receiving $4 \mathrm{~g}$ EPA lost a median of $0.4 \mathrm{~kg}$. The 
weight of patients with gastrointestinal cancer who received EPA, increased significantly compared with placebo. In contrast, the weight of those patients with lung cancer showed no significant response. However, there was no demonstration that the two groups were responding differently to EPA, because a test of interaction was not significant $(p=0.155)$. A possible explanation for this, could be the differential expression of pro-inflammatory cytokines and other pro-cachectic molecules in different cancer types. Analysis of covariance for LBM between the 3 groups in the intention-to-treat analysis at 8 weeks, showed a non-significant result $(p=0.14)$. When compared with the placebo group, the mean change in LBM for the group receiving $2 \mathrm{~g} /$ day of EPA was an increase of $0.9 \mathrm{~kg}$. For the group receiving $4 \mathrm{~g} /$ day of EPA, LBM decreased of $0.1 \mathrm{~kg}$. Compared with LBM at baseline, patients receiving placebo lost a mean of $0.3 \mathrm{~kg}$ over 8 weeks. Those receiving $2 \mathrm{~g} / \mathrm{day}$ of EPA gained a median of $0.6 \mathrm{~kg}$ and those receiving $4 \mathrm{~g}$ of EPA lost a median of $0.4 \mathrm{~kg}$. There was a statistically significant difference in physical function at 8 weeks between the study groups and those receiving placebo. Physical function improved by approximately $7 \%$ compared with placebo in those receiving $2 \mathrm{~g}$ EPA $(p=0.04)$ and fell by around $5 \%$ in those receiving $4 \mathrm{~g}$ EPA. There was also a trend toward a difference in levels of self-reported weakness between experimental groups vs placebo. Weakness tended to decrease in the $2 \mathrm{~g}$ EPA group at 4 and 8 weeks, whereas there was little change in the $4 \mathrm{~g}$ EPA group. Median survival from baseline of patients receiving placebo was 140 days. Patients receiving $2 \mathrm{~g}$ EPA had a median survival of 155 days, and those receiving $4 \mathrm{~g}$ EPA had a median survival of 142 days. There were no differences in CRP, albumin, KPS or appetite between groups or at any time point in either the intention-to-treat or perprotocol groups. No benefits were observed with 4g EPA per day diethyl ester preparation, but a potentially clinically relevant treatment effect with $2 \mathrm{~g}$ EPA per day. One explanation might be that a higher dose of EPA gave rise to nonspecific gastrointestinal adverse effects, which might have caused a net decline in food intake and hence nutritional status. However, in this study, self-reported levels of gastrointestinal symptoms were similar at 4 weeks and 8 weeks in the 3 groups, suggesting that any adverse effects of $4 \mathrm{~g}$ per day of EPA diethyl ester were relatively subtle. Future cachexia trials would benefit from studying a single tumour type in an earlier stage disease.

The study by Pastore, et al 2014 aimed to evaluate compliance of cancer patients to EPA enriched supplementation at the beginning of chemotherapy and its 
effects on inflammation. Overall 69 patients with gastrointestinal tract or lung cancer were recruited, who were about to initiate their first course of chemotherapy. There were 57 patients in the intention-to-treat analyses, and 43 patients in protocol analyses. Patients were instructed to take Oral Nutritional Supplement (ONS), 3 days before the first chemotherapy course and to continue taking it daily for 4 weeks. IG: three $125 \mathrm{~mL}$ units enriched with 2.2g EPA/day; and CG: two 200mL units of standard ONS. After this period, patients returned for the final evaluation of their clinical data, nutritional assessment, and CRP measurements. In the intention-to-treat analysis, the IG had a variation of $-0.5 \mathrm{mg} / \mathrm{dL}$ between the onset and final CRP values; whereas in the CG, variation was $-0.7 \mathrm{mg} / \mathrm{dL},(p=0.6)$. However, in the per protocol analysis, we observed a variation of $-2.35 \mathrm{mg} / \mathrm{dL}$ in the IG and $-0.7 \mathrm{mg} / \mathrm{dL}$ in the $\mathrm{CG}$, showing a non-significant trend toward a decrease in the EPA group $(p=0.8)$. The absence of significance could be due to a lack of statistical power because of the small sample size. Regarding the initial inflammation level according to the cancer location, lung tumours showed the highest CRP levels (58), followed by colon/rectum tumours (14.9), whereas pancreas and gallbladder tumours showed a median CRP of 0.8. This difference was not related to the stage of the disease $(p>0.5)$. This finding suggests that not all types of tumours have the same inflammatory response profile, and some of them like lung cancer, may need higher amounts of EPA supplementation to modulate inflammation. Besides the fact that the protocol dose for the EPA supplement used in this study was $2.2 \mathrm{~g} / \mathrm{day}$, a substantial number of patients interrupted the treatment or reduced their daily dose. Therefore, results might have been affected by insufficient EPA intake. Greater disease severity on more that $50 \%$ of the sample, may have also contributed to lack of effect of EPA in such serious condition.

Echuim oil is a plant-based alternative extracted from the seeds of Echium plantagineum, containing significant amounts of the n-3 PUFA $\alpha$-linolenic acid (ALA) and stearidonic acid (SDA), as well as n-6 PUFA $\gamma$-linolenic acid (GLA) and has been suggested as an alternative for vegetarians to benefit from the anti-inflammatory effects of long-chain n-3 polyunsaturated fatty acids (LCPUFA). SDA is the product of the rate-limiting $\Delta 6$-desaturase step and therefore more readily converted to EPA, than when consuming ALA (conversion rate 17-30\% vs 0.2-8\%). Moreover, supplementation with SDA in combination with GLA has been suggested to work synergistically in increasing anti-inflammatory effects through increases in EPA and dihomo-GLA (DGLA) concentrations. 
A study by Pottel et al, 2014 primarily aimed to examine the effect of echium oil as an alternative source of n-3 PUFA, to reduce weight loss in head-neck (HN) cancer patients undergoing curative radio-chemotherapy. Of the 85 patients who initiated the dietary supplement, body weight loss was collected in 83 of them. Patients in the IG were asked to consume $7.5 \mathrm{~mL} /$ day of echium oil (containing $235 \mathrm{mg} / \mathrm{mL}$ ALA + $95 \mathrm{mg} / \mathrm{mL}$ SDA $+79 \mathrm{mg} / \mathrm{mL}$ GLA) from treatment initiation, until the end of their 7 week treatment. Patients in the CG received a placebo, containing the same volume of n-3 PUFA deficient sunflower oil. No significant difference in weight loss was observed between the IG (8.9\%) vs the CG (7.6\%) ( $p=0.303)$. After 4 weeks of dietary supplement intake, a significant decrease in FFM was seen (IG: $-5.10 \%$, CG: $-2.41 \%$, $p<0.01$ ), Lean Mass (LM) (IG: $-3.77 \%$, CG: $-2.41 \%, p<0.01)$ and Fat Mass (FM) (IG:4.04\%, CG:-3.66\%, $p<0.05)$ was observed in both groups with Dual energy X-ray Absorptiometry (DXA) evaluation (gold standart). The relative median decrease in grip strength throughout treatment was comparable between both groups (IG: $-0.86 \%$ vs CG: $-0.78 \%, p>0.05)$. Based on conversion rates observed in healthy people, one could argue that consumption of the echium oil as applied in this trial would result in a daily EPA dosage that is approximately half of the minimum effective dosage of $1.5 \mathrm{~g}$. The required daily echium oil volume intake would significantly have to increase in order to obtain comparable dosages EPA as found in fish oil (e.g. 2.4g EPA would required $60 \mathrm{~mL}$ echium oil). Intake of larger volumes of echium oil might not be feasible under radio-chemotherapy, but administration of echium oil already at time of diagnosis or after the end of treatments, may possibly increase patient adherence and might therefore be worth exploring in the future.

\section{Discussion}

Multiple biologic pathways are involved in cachexia, including immune response, neuroendocrine hormones and tumour specific factors such as PIF. Omega-3 is known to reduce synthesis and secretion of cytokines, attenuate protein degradation by preventing NF-kB accumulation in the nucleus and inhibit the effects of PIF. Therefore, it would be expected that omega-3 have a role in nutritional support of cancer patients and attenuate the weight loss or even lead to weight gain, increase appetite, improve QoL and prolong survival. 
Of note that all 7 study comprehensively discussed in this article have high quality (>3 point) using the Delphi List (21). The only study that was statistically positive $(14,15)$ was also the only that was undertaken in a pre-cachectic study population, with a less advanced disease stage and a low prevalence of malnutrition at baseline. The other 5 studies was statistically negative. In Moses et al, 2004, patients were included in the study if they had lost more than $5 \%$ of their pre-illness stable weight over the previous 6 months. There were no significant changes in weight or LBM in either group, but TEE, EEA, PAL and energy+protein intake all increased significantly in those randomised to the n-3 enriched supplement, but not in the control group, over the 8-week period.

In the clinical trial by Jatoi, et al, 2004, patients were required to have a selfreported, 2-month weight loss of at least $2.3 \mathrm{~kg}$ and/or a physician-estimated caloric intake of less than 20 calories $/ \mathrm{kg}$ of body weight $/ \mathrm{d}$ and the primary end point was a $10 \%$ weight gain above baseline. The primary end point indicated greater efficacy with single-agent Megesterol Acetate. However, when weight gain was evaluated with increments of less than $10 \%$ weight increase, there seemed to be no significant differences among the arms. MA is known to improve appetite and weight (increase in fat mass). In this study there were no differences in appetite among treatment arms, suggesting that the EPA supplement might actually carry at least modest orexigenic effects. In the other hand, when weight was evaluated with increments of less than $10 \%$, there were no significant differences, which mean that EPA supplement also increase or stabilize weight, and it seems likely that MA might have masked some of the favourable effects of EPA.

In the study by Fearon et al, 2006, patients had gastrointestinal and lung cancer and weight loss of $5 \%$ or more of pre-illness stable weight. At baseline, patients had lost approximately $18 \%$ of their pre-illness body weight and had a BMI of about $21 \mathrm{~kg} / \mathrm{m}^{2}$ (indicating moderately severe undernutrition). This study compared two doses of EPA (2 and $4 \mathrm{~g}$ ) with the placebo group. There was an increase in LBM, a decrease in weakness and a statistically significant difference in physical function in the $2 \mathrm{~g}$ EPA group. It was also seen that the weight of patients with gastrointestinal cancer increased significantly compared with lung cancer. A possible explanation for this could be the different expression of pro-inflammatory cytokines and other pro-cachectic molecules in different cancer types. 
In the study by Pastore, et al 2014, patients had a more advanced stage. There was a non-significant trend toward a decrease of CRP values in the EPA group. The absence of significance could be due to a lack of statistical power because of the small sample size. Regarding the initial inflammation level, lung tumours showed highest CRP levels (58), followed by colorectal tumours (14.9), whereas pancreas and gallbladder tumours showed median CRP of 0.8 . This difference was not related to the stage of the disease. This finding suggests again that different types of tumours show different inflammatory response profile, and lung cancer may need higher amounts of EPA supplementation to achieve an inflammatory modulation.

Finally, in the study by Pottel, et al, 2014 examined the effect of echium oil as an alternative source of n-3 PUFA. There were no differences between groups, which could be because the required daily echium oil volume intake would significantly have to increase in order to obtain comparable dosages EPA as found in fish oil.

Future cachexia trials, would likely benefit from studying a single tumour type, at an earlier stage disease, and different dosage depending on the type and inflammation profile. Intervention in patients undergoing radio or chemotherapy may lead to a decrease in compliance, with interruption in the treatment or reduction in their daily dose. It is possible that patients associate the side effects of chemotherapy (taste change, loss of appetite, nausea, vomiting and sore mouth) to EPA supplementation. Therefore, the results of the studies may be affected by an insufficient EPA dose ingestion. Perhaps a better adherence could be obtained if EPA was given after adaptation to chemotherapy, when patients are able to recognize its side effects, thus avoiding a biased association with EPA (19). 


\section{References}

(1) - DeFilippis AP, and Sperling LS. Understanding omega-3's. American Heart Journal 2006; 151:564-70.

(2) - Gleissman H, Johnsen JI, Kogner P. Omega-3 fatty acids in cancer, the protectors of good and the killers of evil!? Experimental cell research 2010; 316:1365-1373.

(3) - Kaur N, Chugh V, Gupta AK. Essential fatty acids as functional components of foods - a review. J Food Sci Technol 2014; 51(10): 2289-2303

(4) - Ries A, Trottenberg P, Elsner F, Stephanie S, Haugen D, Kaasa S, Radbruch L. A systematic review on the role of fish oil for the treatment of cachexia in advanced cancer: An EPCRC cachexia guidelines project. Palliative Medicine 2011; 26(4): 294-304

(5) - Symington EA, Gericke GJ. The role of long-chain polyunsaturated fatty acids in the treatment of cancer cachexia and tumour growth in patients with malignant diseases: a review. Health Sa Gesondheid 2008; Vol.13 No.2: 49-60

(6) - Hardman WE. (n-3) Fatty Acids and Cancer Therapy. The Journal of Nutrition 2004; 134(12 Suppl): 3427S-3430S

(7) - Surette ME. The science behind dietary omega-3 fatty acids. CMAJ 2008; 178(2): $177-180$

(8) - Anderson BM and Ma DWL. Are all n-3 polyunsaturated fatty acids created equal?. Lipids in Health and Disease 2009; 8:33

(9) - Gullett NP, Mazurak V, Hebbar G and Ziegler TR. Nutritional Interventions for Cancer-Induced Cachexia. Curr Probl Cancer 2011; 35:58-90

(10) - Giacosa A and Rondanelli M. Fish oil and treatment of cancer cachexia. Genes Nutr 2008; 3:25-28

(11) - Mantovani G and Madeddu C. Cancer cachexia: medical management. Support Care Cancer 2010; 18:1-9

(12) - Kumar NB, Kazi A, Smith T, Crocker T, Yu D, Reich RR, Reddy K, Hastings S, Exterman M, Balducci L, Dalton K, Bepler G. Cancer Cachexia: Traditional Therapies and Novel Molecular Mechanism-Based Approaches to Treatment. Current Treatment Options in Oncology 2010; 11:107-117

(13) - Berquin IM, Edwards IJ, Chen YQ. Multi-targeted Therapy of Cancer by Omega-3 Fatty Acids. Cancer Lett. 2008; 269(2):363-377

(14) - van der Meij BS, Langius JAE, Smit EF, Spreeuwenberg MD, von Blomberg BME, Heijboer AC, Paul MA and van Leeuwen PAM. Oral Nutritional 
Supplements Containing (n-3) Polyunsaturated Fatty Acids Affect the Nutritional Status of Patients with Stage III Non-Small Cell Lung Cancer during Multimodality Treatment. J. Nutr. 2010; 140: 1774-1780

(15) - van der Meij BS, Langius JAE, Spreeuwenberg MD, Slootmaker SM, Paul MA, Smit EF and van Leeuwen PAM. Oral nutritional supplements containing $n-3$ polyunsaturated fatty acids affect quality of life and functional status in lung cancer patients during multimodality treatment: an RCT. European Journal of Clinical Nutrition 2012; 66: 399-404

(16) - Moses AWG, Slater C, Preston T, Barber MD and Fearon FCH. Reduced total energy expenditure and physical activity in cachectic patients with pancreatic cancer can be modulated by an energy and protein dense oral supplement enriched with n-3 fatty acids. British Journal of Cancer 2004; 90: 996-1002

(17) - Jatoi A, Rowland K, Loprinzi CL, Sloan JA, Dakhil SR, MacDonald N, Gagnon B, Novotny PJ, Mailliard JA, Bushey TIL, Nair S and Christensen B. An Eicosapentaenoic Acid Supplement Versus Megestrol Acetate Versus Both for Patients With Cancer-Associated Wasting: A North Central Cancer Treatment Group and National Cancer Institute of Canada Collaborative Effort. J Clin Oncol 2004; 22:2469-2476

(18) - Fearon KCH, Barber MD, Moses AG, Ahmedzai SH, Taylor GS, Tisdale MJ and Murray GD. Double-Blind, Placebo-Controlled, Randomized Study of Eicosapentaenoic Acid Diester in Patients With Cancer Cachexia. J Clin Oncol 2006; 24:3401-3407

(19) - Pastore CA, Orlandi SP, Gonzalez MC. Introduction of an Omega-3 Enriched Oral Supplementation for Cancer Patients Close to the First Chemotherapy: May It Be a Factor for Poor Compliance?. Nutrition and Cancer 2014; 66(8):1285-1292

(20) - Pottel L, Lycke M, Boterberg T, Pottel H, Goethals L, Duprez F, Maes A, Goemaere S, Rottey S, Foubert I and Debruyne PR. Echium oil is not protective against weight loss in head and neck cancer patients undergoing curative radio(chemo)therapy: a randomised-controlled trial. BMC Complementary and Alternative Medicine 2014; 14:382

(21) - Jadad AR, Moore RA, Carroll D, Jenkinson C, Reynolds DJ, Gavaghan DJ, McQuay HJ. Assessing the quality of reports of randomized clinical trials: is blinding necessary? Control Clin Trials 1996; 17(1):1-12 